\title{
SEGMENTASI PELANGGAN E-MONEY DENGAN MENGGUNAKAN ALGORITMA DBSCAN (DENSITY BASED SPATIAL CLUSTERING APPLICATIONS WITH NOISE) DI PROVINSI DKI JAKARTA
}

\author{
Windy Rohalidyawati ${ }^{1}$, Rita Rahmawati ${ }^{2}$, Mustafid ${ }^{3}$ \\ 1,2,3 Departemen Statistika, Fakultas Sains dan Matematika, Universitas Diponegoro \\ e-mail :windyrohali@gmail.com
}

\begin{abstract}
Customer segmentation is one effective way of marketing to determine the most potential target market. Increasing of E-money us age in DKI Jakarta and more banks are providing E-money products. One way to be able to compete in the global market, banks can segment customers. Determining potential customers of Emoney users in DKI Jakarta can form segments by applying the DBSCAN (Density Based SpatialClustering Application with Noise) algorithm. The quality of segments was measured by using the Silhouette Coefficient. In this study, E-money customers were grouped by reas on of using the bank used, transaction activities, number of transactions, nominal balance, and frequency of top-up. The results of this study were using the density radius of 2 and minimum 3 objects that enter the density radius forming 2 segments and 17 noises. The segment quality value of 0.26 . The most potential segment was the segment that has an average greater than the average of all data.
\end{abstract}

Keywords: Costumer segmentation, E-money, clustering, DBSCAN

\section{PENDAHULUAN}

Menurut Bank Indonesia (BI), secara sederhana uang elektronik didefinisikan sebagai alat pembayaran dalam bentuk elektronik di mana nilai uangnya disimpan dalam media elektronik tertentu. Produk-produk uang elektronik dibagi menjadi dua jenis yaitu $E$ money dan E-wallet. E-money adalah uang elektronik berbasis chip yang ditanam pada kartu atau media lainnya (chip based). Sedangkan E-wallet adalah uang elektronik yang berbasis server dalam bentuk aplikasi.

Menurut Bank Indonesia (BI), terdapat 36 penyelenggara uang elektronik dan 11 diantaranya adalah penyelenggara E-money. Melihat banyaknya penyelenggara E-money, pihak penyelenggara harus menentukan target pemasaran yang tepat. Salah satu langkah yang dapat dilakukan dalam menentukan target pemasaran adalah membuat segmensegmen pasar. Untuk memudahkan segmentasi pasar dapat dilakukan dengan analisis cluster atau sering disebut dengan clustering.

Salah satu metode clustering yang dapat digunakan adalah DBSCAN (Density Based Spatial Clustering Applications with Noise). Algoritma DBSCAN termasuk algoritma nonparametrik dalam unsupervised learning sehingga tidak memerlukan asumsi dalam pengerjaannya. Secara konsep DBSCAN dapat membentuk cluster-cluster yang berbentuk bebas dan acak (tidak bulat) dan dapat mempermudah membentuk cluster jika terdapat noise atau pencilan pada cluster-cluster tersebut. Algoritma ini menumbuhkan daerah yang memiliki kerapatan tinggi menjadi cluster-cluster menggunakan dua parameter yang harus ditentukan dengan tepat, parameter tersebut adalah radius ketegangan, yang disimbolkan dengan $\varepsilon$, dan minimum objek (minObj) yang menjadi batas kepadatan (density threshold) untuk menentukan suatu region termasuk padat atau tidak, yang disimbolkan MinObj (Suyanto, 2019).

Penelitian ini bertujuan untuk menerapkan algoritma DBSCAN (Density Based Spatial Clustering Application with Noise) dalam membentuk segmen-segmen dari pelanggan E-money di provinsi DKI Jakarta untuk menentukan pelanggan potensial serta 
menentukan kualitas dari segmen-segmen yang telah terbentuk dengan menggunakan Silhouette Coefficient.

\section{TINJAUAN PUSTAKA}

\subsection{Uang Elektronik}

Menurut Bank Indonesia (BI), secara sederhana uang elektronik didefinisikan sebagai alat pembayaran dalam bentuk elektronik di mana nilai uangnya disimpan dalam media elektronik tertentu. Penggunaan uang elektronik ini sebagai alat pembayaran yang inovatif dan praktis diharapkan dapat membantu kelancaran pembayaran kegiatan ekonomi yang bersifat massal, cepat dan mikro, sehingga perkembangannya dapat membantu kelancaran transaksi di jalan tol, di bidang transportasi seperti kereta api maupun angkutan umum lainnya atau transaksi di minimarket, food court, atau parkir.

\subsection{Segmentasi Pasar}

Segmentasi pasar adalah proses di mana pasar dibagi menjadi para pelanggan yang terdiri atas orang-orang dengan kebutuhan dan karakteristik yang sama yang mengarahkan pelanggan untuk merespon tawaran produk/jasa dan program pemasaran strategis tertentu dalam cara yang sama (Boyd JR et al, 2000). Keuntungan dari segmentasi pasar adalah menemukan pasar yang dapat meningkatkan keuntungan perusahaan dan mengidentifikasi pelanggan yang paling menguntungkan (Goyat, 2011). Pelanggan potensial adalah pelanggan yang mendorong keuntungan paling besar untuk perusahaan (Yankelovich, 2006).

\subsection{Sampling}

Teknik pengambilan sampel (sampling) adalah cara peneliti mengambil sampel atau contoh yang representatif dari populasi yang tersedia. Cara pengambilan sampel dari populasi dapat dilakukan dengan memperhatikan unsur peluang atau tidak. Jika dalam proses mengambil sampel memperhatikan unsur peluang, tipe sampling disebut sampling peluang (probability sampling) atau cara pengambilan sampel secara acak. Jika dalam proses pengambilan sampel tidak memperhatikan unsur peluang, tipe sampling disebut sampling nonpeluang (non-probability sampling (Sanusi, 2011).

\subsection{Quota Sampling}

Quota sampling digunakan untuk memastikan bahwa berbagai subgroup dalam populasi telah terwakili dengan berbagai karakteristik sampel sampai batas tertentu seperti yang dikehendaki oleh peneliti. Dalam quota sampling, peneliti menentukan target kuota yang dikehendaki. Keunggulan sampel kuota adalah memungkinkan pengumpulan data dengan cepat dan biaya yang rendah. Kelemahan dari sampel kuota adalah adanya kemungkinan bias karena responden dipilih berdasarkan prosedur convenience sampling dan bukan berdasarkan metode probabilitas (misalnya sampel stratifikasi) (Kuncoro, 2009).

\subsection{Data Mining}

Data mining sering juga disebut knowledge discovery in database (KDD) yang artinya adalah kegiatan yang meliputi pengumpulan, pemakaian data historis untuk menemukan keteraturan, pola atau hubungan dalam dataset berukuran besar. Keluaran dari data mining ini dapat digunakan untuk memperbaiki pengambilan keputusan di masa depan (Santosa, 
2007). Salah satu langkah dalam data mining adalah preprocessing data. Pada preprocessing data, salah satu yang dapat dilakukan adalah melakukan normalisasi data. Nilai-nilai atribut data yang berbeda-beda rentangnya perlu dinormalisasi atau distandarisasi agar proses data mining tidak bias. Salah satu metodenya yaitu normalisasi min-maks.

Misalkan $A$ adalah atribut bertipe numerik, $\min _{A}$ adalah nilai minimum dalam atribut $A$, maks $_{A}$ adalah nilai maksimum dalam atribut $A$. Suatu nilai $x_{\mathrm{i}}$ dapat dinormalisasi menjadi nilai baru $x_{i}^{\prime}$ yang berada dalam rentang $\left[\operatorname{minbaru}_{A}, \operatorname{maks} \mathrm{aru} u_{A}\right]$ dengan formula (Suyanto, 2019):

\subsection{Analisis Cluster}

$$
x_{i}^{\prime}=\frac{x_{i}-\min _{A}}{\operatorname{maks}_{A}-\min _{A}}\left(\operatorname{maksbaru}_{A}-\operatorname{minbaru}_{A}\right)+\operatorname{minbar}_{A}
$$

Analisis Cluster adalah istilah yang diberikan pada sebuah teknik yang digunakan untuk mengidentifikasi objek atau individu yang serupa dengan memperhatikan beberapa kriteria. Tujuan utama analisis cluster adalah untuk menggolongkan individu atau objek yang berhubungan secara mutually exclusive ke dalam jumlah yang lebih kecil. Sebuah cluster harus memiliki homogenitas internal (dalam satu cluster) yang tinggi dan heterogenitas eksternal (antar cluster) yang tinggi (Kuncoro, 2009).

\subsection{Jarak Euclidean}

Untuk data yang memiliki atribut numerik terdapat formula pengukuran jarak salah satunya adalah Jarak Euclidean. Jarak Euclidean adalah jarak antara dua objek data $(i, j)$ dari $n$ atribut bernilai numerik, yang dinyatakan sebagai $\boldsymbol{i}=x_{i 1}, x_{i 2}, \ldots, x_{i n}$ dan $\boldsymbol{j}=$ $x_{j 1}, x_{j 2}, \ldots, x_{j n}$ pada ruang dimensi $n\left(R^{n}\right)$ (Suyanto, 2019):

$$
d(i, j)=\sqrt{\left(x_{i 1}-x_{j 1}\right)^{2}+\left(x_{i 2}-x_{j 2}\right)^{2}+\cdots+\left(x_{i n}-x_{j n}\right)^{2}}
$$

\subsection{DBSCAN}

Prinsip-prinsip dasar dari DBSCAN adalah sebagai berikut (Silitonga, 2016):

1. Neighborhood yang terletak di dalam radius $\varepsilon$ disebut dengan $\varepsilon$-neighborhood dari objek data.

2. Jika E-neighborhood dari suatu objek adalah jarak terkecil dalam sebuah cluster, objek tersebut disebut core object.

3. Suatu objek $p$ adalah density reachable dari objek $q$ dengan respek ke $\boldsymbol{\varepsilon}$ dan minObj dalam suatu set objek $\mathrm{D}$ jika terdapat suatu rantai objek $p_{1}, p_{2}, \ldots, p_{n}$, dengan $p_{1}=q$ dan $p_{n}=p$, dengan $p_{i+1}$ density reachable secara langsung dari $p_{i}$ dengan respek ke $\varepsilon$ dan minObj, untuk $1 \leq i \leq n, p_{i}$ anggota $\mathrm{D}$.

4. Suatu objek $p$ adalah density connected ke objek $q$ dengan respek ke $\varepsilon$ dan minObj dalam suatu set objek D jika terdapat suatu objek $o$ anggota D dengan ke dua $p$ dan $q$ adalah density reachable dari $o$ dengan respek ke $\boldsymbol{\varepsilon}$ dan minObj.

\subsection{Penentuan Eps ( $\varepsilon$ ) dan MinObj}

Untuk menentukan $\varepsilon$ dan MinObj yang optimal dapat dilakukan dengan membuat $k$ dist graph dengan melihat pergeseran nilai $\varepsilon$ dari nilai $k$ yang bervariasi. Titik dimana akan terjadi perubahan tajam pada $k$-dist akan digunakan sebagai $\varepsilon$ dan nilai $k$ digunakan sebagai MinObj (Purwanto, 2012). 


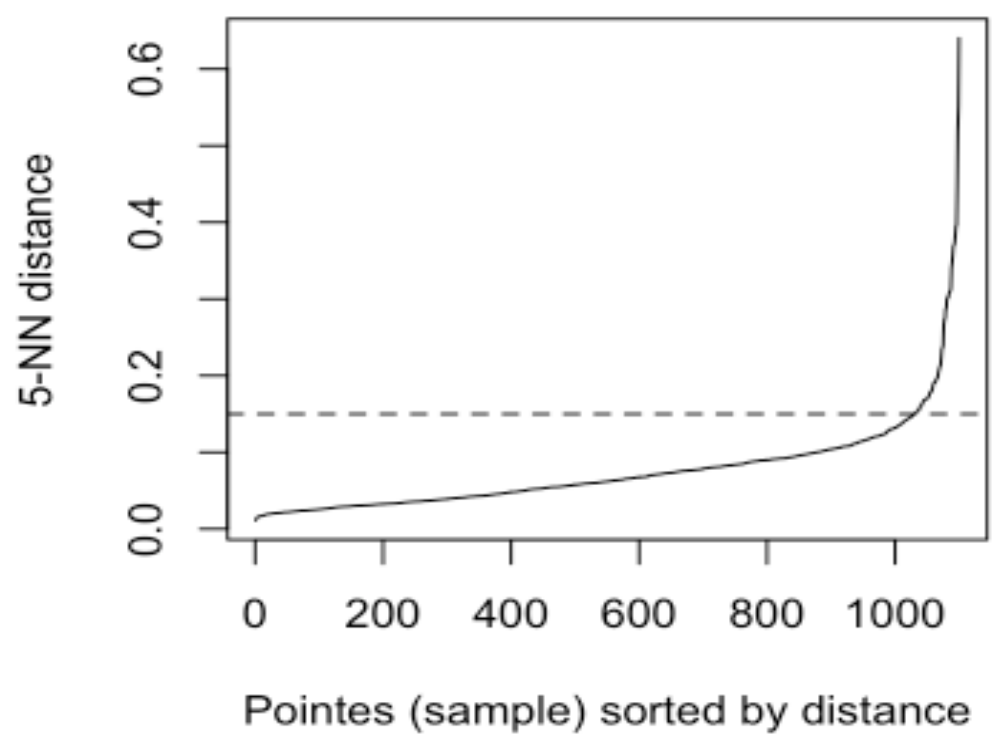

\subsection{Algoritma DBSCAN}

Pengelompokan dengan menggunakan DBSCAN secara umu dilakukan dengan algoritma sebagai berikut (Suyanto, 2019):

1. Tandai semua $D$ sebagai "unvisited"

2. Pilih sebuah objek $p$ kemudian tandai sebagai "visited"

3. Uji apakah dalam radius $\varepsilon$ objek p memiliki minimal MinObj objek tetangga

4. Jika iya sebuah cluster $\mathrm{C}$ akan terbentuk, tambahkan objek p ke $\mathrm{C}$

5. Jadikan $\mathrm{N}$ sebagai objek-objek dalam $\varepsilon$-neighborhood dari $\mathrm{p}$

6. Lakukan secara iteratif kepada object yang masih bertanda unvisited.

7. Jika sebuah objek dalam radius $\varepsilon$ tidak memiliki minimal MinObj objek tetangga, maka ditandai sebagai noise.

\subsection{Pengukuran Kualitas Cluster}

Kualitas cluster diukur menggunakan Silhouette Coefficient. Nilai $a(i)$ menyatakan kepadatan cluster yang mengandung objek $i$. semakin kecil nilai $a(i)$, semakin padat cluster tersebut. Sementara itu, nilai $b(i)$ menggambarkan seberapa jauh objek $i$ terpisah dari cluster-cluster lain. Jadi, jika $a(i)$ bernilai sangat kecil dan $b(i)$ bernilai sangat besar, maka Silhouette Coefficient dari $i$ akan mendekati satu. Sebaliknya, jika $a(i)$ bernilai sangat besar dan $b(i)$ bernilai sangat kecil, maka Silhouette Coefficient dari $i$ akan mendekati -1. Jika Silhouette Coefficient dari $i$ mendekati 1, maka hal ini berarti cluster yang berisi objek $i$ sangat padat dan objek $i$ terpisah jauh dari cluster-cluster lain. Sebaliknya, jika Silhouette Coefficient dari $i$ mendekati -1, maka hal ini berarti cluster yang berisi objek $i$ tidak padat dan objek $i$ sangat dekat (bahkan tumpang tindih) dengan cluster-cluster lain (Suyanto, 2019).

$$
s(i)=\frac{b(i)-a(i)}{\max \{a(i), b(i)\}}
$$




\section{METODE PENELITIAN}

\subsection{Data Penelitian}

Pengambilan sampel dilakukan kepada pelanggan E-money yang berdomisili di 5 kota di Provinsi DKI Jakarta, yaitu Jakarta Timur, Jakarta Barat, Jakarta Selatan, Jakarta Utara, dan Jakarta Pusat. Responden pada penelitian ini adalah penduduk DKI Jakarta dari 5 kelompok umur 15-19 tahun, 20-24 tahun, 25-29 tahun, 30-34 tahun, dan 35-39 tahun. Jumlah sampel yang diambil sebanyak 180 orang.

\subsection{Tahapan Analisis Data}

Analisis cluster ini dilakukan dengan bantuan software Ri386.3.5.2. Tahap-tahap yang dilakukan dalam segmentasi pelanggan E-money adalah sebagai berikut:

1. Menentukan sampel dengan Quota Sampling:

a. Menentukan total jumlah sampel yang akan diambil.

b. Mencari jumlah populasi penduduk Provinsi DKI Jakarta berdasarkan umur dan kota.

c. Menghitung kuota sampel berdasarkan umur dari populasi penduduk di kota Jakarta Utara, Jakarta Barat, Jakarta Pusat, Jakarta Timur, dan Jakarta Selatan

2. Membuat kuesioner.

3. Melakukan pengumpulan data melalui kuesioner online.

4. Melakukan preprocessing data dengan melakukan normalisasi min-max.

5. Melakukan analisis segementasi pelanggan E-money dari data yang telah dinormalisasi. Analisis segmentasi pelanggan E-money menggunakan algoritma Density-Based Spatial Clustering Algorithm with Noise (DBSCAN):

a. Menentukan nilai parameter MinObj dan $\varepsilon$ berdasarkan $k$-dist

b. Memilih titik p secara acak, berdasarkan MinObj dan $\varepsilon$ yang telah dipilih dengan menghitung jarak titik p dengan titik lainnya menggunakan Jarak Euclidean.

c. Ambil semua titik yang menjadi tetangga titik $\mathrm{p}$ yang masuk ke dalam radius $\varepsilon$ dan memiliki MinObj objek tetangga.

d. Setelah diketahui semua titik yang menjadi tetangga titik $\mathrm{p}$, pilih jarak yang terkecil sebagai core object. Apabila titik p merupakan core object maka cluster mulai terbentuk.

e. Apabila $\mathrm{p}$ adalah border dan semua titik yang menjadi tetangga titik $\mathrm{p}$ sudah dikunjungi, maka proses dilanjutkan ke titik yang lain.

f. Melakukan kembali langkah a sampai dengan e hingga semua titik telah diproses. Jika terdapat titik yang bukan termasuk dalam cluster maka disebut dengan noise.

g. Melakukan pengukuran kualitas cluster menggunakan Silhouette Coefficient terhadap cluster yang telah dibentuk dari algoritma DBSCAN.

h. Melakukan interpretasi hasil dari terbentuknya cluster-cluster yang terbentuk dari algoritma DBSCAN.

\section{HASIL DAN PEMBAHASAN}

\subsection{Penarikan Sampel}

Sampel yang diambil dalam penelitian ini adalah pengguna E-money yang merupakan penduduk DKI Jakarta yang berusia 15-19 tahun, 20-24 tahun, 25-29 tahun, 30-34 tahun, 35-39 tahun dan berdomisili di Jakarta Pusat, Jakarta Utara, Jakarta Barat, Jakarta Selatan dan Jakarta Timur. Sampel diambil sebanyak 180 orang. 


\subsection{Analisis Deskriptif}

Pertama dilakukan analisis deskriptif untuk mendapatkan gambaran umum mengenai data penelitian yang sudah terkumpul.

Tabel 1. Analisis Desk riptif Pelanggan E-money

\begin{tabular}{lccccc}
\hline \multicolumn{1}{c}{ Variabel } & N & Minimum & Maksimum & Mean & StDev \\
\hline Saldo & 180 & Rp. 2.000 & Rp. 850.000 & Rp. 113.955 & Rp. 125.698 \\
Top-up & 180 & 1 & 30 & 3 & 4 \\
Transaksi & 180 & 0 & 10 & 2 & 1 \\
Alasan & 180 & 1 & 8 & 3 & 2 \\
Kegiatan & 180 & 1 & 6 & 3 & 1 \\
\hline
\end{tabular}

\subsection{Pe nentuan Eps (ع) dan MinObj yang Optimal}

Pada DBSCAN pemilihan parameter Eps $(\varepsilon)$ dan MinObj yang optimal dipilih berdasarkan k-dist graph. Komputasi dilakukan untuk mendapatkan nilai k-dist pada nilai $\mathrm{k}$ yang bervariasi. K-dist dicari pada titik $\mathrm{k}=2$ dan $\mathrm{k}=3$. Dilihat pada Gambar 1 dan Gambar 2 , jika menggunakan $\mathrm{MinObj}=2$ maka $\varepsilon$ yang optimal adalah 0,25 sampai dengan 0,3 dan jika menggunakan $\mathrm{MinObj}=3$ maka $\varepsilon$ yang optimal adalah 0,25 sampai dengan 0,3 .

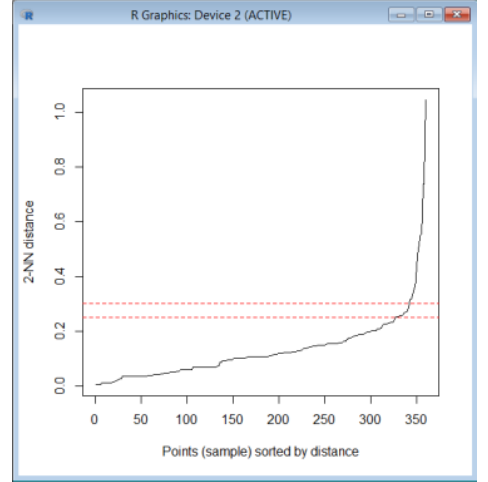

Gambar 1. K-dist dengan $k=2$

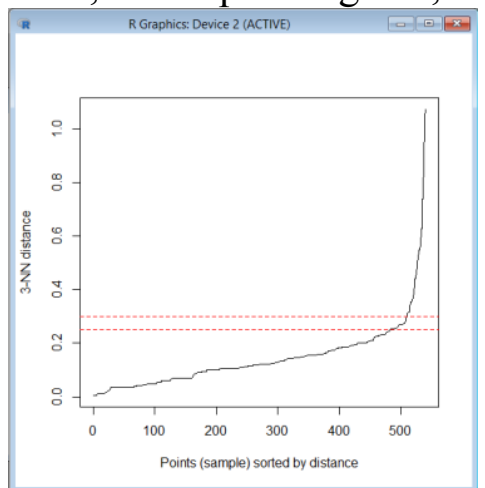

Gambar 2. K-dist dengan k=3

\subsection{Jarak Euclidean}

Segmen pelanggan E-money dibentuk menggunakan algoritma DBSCAN memerlukan jarak antar objek. Jarak antar objek dihitung menggunakan jarak Euclidean, hasil perhitungan jarak antar objek dapat dilihat pada Tabel 2.

Tabel 2. Perhitungan Jarak Euclidean

\begin{tabular}{lr}
\hline$(\mathbf{i}, \mathbf{j})$ & $\mathbf{d}(\mathbf{i}, \mathbf{j})$ \\
\hline$(1,1)$ & 0 \\
$(1,2)$ & 0,335377 \\
$(1,3)$ & 0,527741 \\
& $\ldots$ \\
$(2,2)$ & 0 \\
$(2,3)$ & 0,835263 \\
$(2,4)$ & 0,403512 \\
& $\ldots$ \\
$(179,179)$ & 0 \\
$(179,180)$ & 0,825511 \\
$(180,180)$ & 0 \\
\hline
\end{tabular}




\subsection{Pembentukan Segmen}

Hasil pembentukan segmen pada data pelanggan E-money menggunakan algoritma DBSCAN di DKI Jakarta dijelaskan pada Tabel 3.

Tabel 3. Hasil Segmentasi Pelanggan E-money dengan Algoritma DBSCAN

\begin{tabular}{lcccc}
\hline MinObj & \multicolumn{3}{c}{3} \\
Eps & 0,25 & 0,3 & 0,25 & 0,3 \\
Banyaknya segmen yang terbentuk & 4 & 1 & 3 & 1 \\
Noise & 13 & 8 & 17 & 8 \\
\hline
\end{tabular}

\subsection{Inte rpre tasi Se gmen}

Berdasarkan Tabel 4, parameter terbaik untuk membentuk segmen pelanggan E-money di DKI Jakarta adalah $\varepsilon=0,3$ pada $\operatorname{minObj}=2$ dan $\operatorname{minObj}=3$ karena memiliki lebih sedikit noise dan memiliki Silhouette Coefficient yang paling besar dibandingkan parameter lainnya. Namun, parameter tersebut hanya menghasilkan 1 segmen sehingga tidak ada segmen pembanding untuk menentukan segmen yang paling potensial. Oleh karena itu, parameter yang digunakan untuk membentuk segmentasi pelanggan E-money di Provinsi DKI Jakarta adalah $\varepsilon=0,25$ dan $\operatorname{minObj}=3$. Parameter tersebut dipilih karena membentuk 2 segmen sehingga dapat dilihat segmen yang paling potensial.

Tabel 4. Interpretasi Segmen yang Terbentuk

\begin{tabular}{lcccc}
\hline MinObj & \multicolumn{2}{c}{2} & \multicolumn{2}{c}{3} \\
Eps $(\varepsilon)$ & 0,25 & 0,3 & 0,25 & 0,3 \\
Banyaknya segmen yang terbentuk & 4 & 1 & 2 & 1 \\
Noise & 13 & 8 & 17 & 8 \\
Rata-rata Silhouette Coefficient & 0,15 & 0,47 & 0,26 & 0,47 \\
\hline
\end{tabular}

Setelah diketahui jumlah segmen yang terbentuk, maka dilakukan interpretasi masingmasing segmen yang dijelaskan pada Tabel 5

Tabel 5. Perbandingan Rata-rata Segmen 1 dan Segmen 2

\begin{tabular}{lccccc}
\hline \multicolumn{1}{c}{ Mean } & Alasan & Kegiatan & Saldo & Top- $\boldsymbol{u p}$ & Transaksi \\
\hline Seluruh data & 3 & 3 & Rp. 113.955 & 3 & 2 \\
Segmen 1 & 2 & 3 & Rp. 87.433 & 2 & 2 \\
Segmen 2 & 1 & 2 & Rp. 500.000 & 2 & 4
\end{tabular}

Dapat dilihat pada Tabel 5 bahwa pengguna E-money dalam segmen 2 adalah pelanggan potensial karena memiliki rata-rata nominal saldo dan banyaknya transaksi lebih besar dari rata-rata seluruh data.

\section{KESIMPULAN}

Berdasarkan k-dist graph parameter Eps $(\varepsilon)$ dan MinObj yang optimal yang MinObj $=2$ dan 3, $\varepsilon=0,25$ dan $\varepsilon=0,3$. Dengan menggunakan Eps $(\varepsilon)$ sebesar 0,25 dan MinObj sebesar 3 menghasilkan nilai Silhouette Coefficient sebesar 0,26 dan 17 noise. Parameter tersebut membentuk 2 segmen yaitu segmen 1 dan segmen 2. Pengguna E-money dalam segmen 2 adalah pelanggan potensial karena memiliki rata-rata nominal saldo dan banyaknya transaksi lebih besar dari rata-rata seluruh data. 


\section{DAFTAR PUSTAKA}

Boyd JR, H. W., Walker, J. O., \& Larreche, J. C. (2000). Manajemen Pemasaran Suatu Pendekatan Strategis dengan Orientasi Global. Jakarta: Penerbit Erlangga.

Goyat, S. (2011). The basis of market segmentation: a critical review of literature. European Journal od Business and Management, 2222-2839.

Indonesia, B. (n.d.). Edukasi Perlindungan Konsumen. Retrieved December 19, 2018, from Bank Indonesia Web Site: https //www.bi.go.id/id/edukasi-perlindungankonsumen/edukasi/produk-dan-jasa-sp/uang-e lektronik/Pages/default.aspx

Kuncoro, M. (2009). Metode Riset untuk Bisnis \& Ekonomi. Jakarta: Penerbit Erlangga.

Purwanto, Barus, U. Y., Adrianto, B., \& Agung, H. (2012). Spatial Hotspots Clustering of Forest and Land Fires using DBSCAN and ST-DBSCAN. Bogor.

Santosa, B. (2007). Data Mining Teknik Pemanfaatan Data untuk Keperluan Bisnis. Yogyakarta: Graha Ilmu.

Sanusi, A. (2011). Metodologi Penelitian Bisnis. Jakarta: Penerbit Salemba Empat.

Silitonga, P. (2016). ANALISIS POLA PENYEBARAN PENYAKIT PASIEN PENGGUNA BADAN NEGARA JAMINAN SOSIAL (BPJS) KESEHATAN DENGAN MENGGUNAKAN METODE DBSCAN CLUSTERING. Jurnal TIMES, 36-39.

Suyanto, D. (2019). Data Mining Untuk Klasifikasi dan Klasterisasi Data. Bandung: Penerbit Informatika.

Yankelovich, D. (2006). New Criteria for Market Segmentation. Harvard Business Review. 